$1352-2310(95) 00425-4$

\title{
SULFUR HEXAFLUORIDE-A POWERFUL NEW ATMOSPHERIC TRACER
}

\author{
MANFRED MAISS, ${ }^{*}$ L. PAUL STEELE, $\uparrow$ ROGER J. FRANCEY, $\uparrow$ \\ PAUL J. FRASER, $†$ RAY L. LANGENFELDS, $†$ NEIL B. A. TRIVETT \\ and INGEBORG LEVIN*
}

*Institut für Umweltphysik, University of Heidelberg, INF 366, 69120 Heidelberg, Germany; †CSIRO Division of Atmospheric Research, Private Bag No. 1, Mordialloc, Victoria 3195, Australia; $\ddagger$ CRC for Southern Hemisphere Meteorology, Monash University, Clayton, Victoria 3168, Australia; and §Atmospheric Environment Service, 4905 Dufferin Street, Downsview/Ontario M3H 5T4, Canada

(First received 20 March 1995 and in final form 25 September 1995)

\begin{abstract}
Long-term observations of the atmospheric trace gas sulfur hexafluoride $\left(\mathrm{SF}_{6}\right)$ at four background monitoring stations, Neumayer, Antarctica (1986-1994), Cape Grim, Tasmania (1978-1994), Izaña, Canary Islands (1991-1994) and Alert, Canada (1993-1994) are presented. These data sets are supplemented by two meridional profiles collected over the Atlantic Ocean (1990 and 1993) and occasional observations at the regional site Fraserdale, Canada (1994). The analytical system and the method of $\mathrm{SF}_{6}$ calibration are described. Compared with data from Neumayer and Izaña reported earlier, measurements are updated for all sites until the end of 1994 and the precision has improved by more than a factor of 2 . With the Cape Grim archived air samples, the atmospheric $\mathrm{SF}_{6}$ chronology is extended by 8 more years back to 1978 . For the period from January 1978 to December 1994 the data confirm a stable and unbroken quadratic rise in tropospheric $S F_{6}$ from 0.50 to $3.11 \mathrm{ppt}$ in the southern hemisphere and for July 1991 to December 1994 from 2.69 to $3.44 \mathrm{ppt}$ in the northern hemisphere. The global mean tropospheric increase rate in late 1994 was $0.225 \mathrm{ppt} \mathrm{yr}^{-1}\left(6.9 \% \mathrm{yr}^{-1}\right)$. The long term trend and interhemispheric gradients are due to industrial production and emission, rising approximately linearly with time and located predominantly $(94 \%)$ in the northern hemisphere. The interhemispheric exchange time $(1.7 \pm 0.2 \mathrm{yr})$ derived from $\mathrm{SF}_{6}$ ground level observations when using a two-box model of the atmosphere is considerably larger if compared to the exchange time derived from two- and three-dimensional models $(1.1 \mathrm{yr})$. The chemical and biological inertness of $\mathbf{S F}_{5}$ up to stratospheric conditions results in an atmospheric lifetime of more than 800 years and makes $\mathrm{SF}_{6}$ a powerful tool for modelling transport processes in the atmosphere. Moreover, the tropospheric $\mathrm{SF}_{6}$ chronology is a very valuable input function for mixing studies in linked compartments like the stratosphere, the hydrosphere and the cryosphere.
\end{abstract}

Key word index: Sulfur hexafluoride, atmospheric trace gas, interhemispheric exchange, GC-ECD.

\section{INTRODUCTION}

Sulfur hexafluoride is an extremely stable atmospheric trace gas produced entirely anthropogenically. Its unique physico-chemical properties make this gas ideally suited for many specialized industrial applications. Most of the $\mathrm{SF}_{5}$ produced worldwide ( $\approx 80 \%$ ) is used in and released from electrical equipment, predominantly Gas Insulated Switchgear (GIS). This primary use started in the 1960s. Historical release estimates are available for the years 1953-1974 rising from 14 to $1200 \mathrm{Mg} \mathrm{SF}_{6} \mathrm{yr}^{-1}$ (Ko et al., 1993, and references therein). For the beginning of the 1980s a world-wide production rate of $2500-4500 \mathrm{Mg} \mathrm{SF}_{6}$ $\mathrm{yr}^{-1}$ is reported (Encyclopedia of Chemical Techno$\log y, 1980$ ) rising approximately linearly since 1970 to an estimated value of $5000-8000 \mathrm{Mg} \mathrm{SF}_{6} \mathrm{yr}^{-1}$ around 1990 (SOLVAY, $\mathrm{SF}_{6}$ producer, personal communication, 1993). These numbers on $\mathrm{SF}_{6}$ production are very rough estimates. Beyond this, the amount of $\mathrm{SF}_{6}$ that is banked inside electrical equipment is highly uncertain. However, observing the global increase of $\mathrm{SF}_{6}$ in the atmosphere provides a reliable accumulation record from which release rates can be calculated. This approach has been used by Maiss and Levin (1994) to model an atmospheric emission history, namely the history of $\mathrm{SF}_{6}$ production assuming different residence times associated with its commercial applications. These results agreed reasonably well with the production estimates.

The accumulation of sulfur hexafluoride in the atmosphere is nearly perfectly described by its release rate due to its long atmospheric life-time of probably 3200 yr (Ravishankara et al., 1993). A minimum estimate of $800 \mathrm{yr}$ is given by Morris et al. (1995). The oceanic sink to date is negligible due to the low water solubility of $\mathrm{SF}_{6}$ (Ostwald solubility coefficient $\approx 1 \%$, Wanninkhof et al., 1991) and a relatively slow 
oceanic deep-water formation rate. Since the very first atmospheric measurements in 1970 (Lovelock, 1971), the $\mathrm{SF}_{6}$ concentration has increased by two orders of magnitude from $0.03 \mathrm{ppt}$ (parts per trillion by mole) to a global mean value of 3 ppt at the end of 1993. This dramatic increase recently brought $\mathrm{SF}_{6}$ into the climatic impact discussion since, on a per molecule basis, the greenhouse effect of $\mathrm{SF}_{6}$ is likely to be one of the highest of any atmospheric trace gas (Rinsland et al., 1990). In fact, the Global Warming Potential for $\mathrm{SF}_{6}$ relative to $\mathrm{CO}_{2}$ on a 100 year time horizon has been estimated to be about 20,000 (Ko et al., 1993; Stordal et al., 1993). Only the present low $\mathrm{SF}_{6}$ concentrations $\left(\approx 10^{-8}\right.$ of $\mathrm{CO}_{2} ; \approx 10^{-2}$ of $\mathrm{CFC}$ ) preclude any actual climatic relevance.

Here we describe the Heidelberg low-level $\mathrm{SF}_{6}$ analysis technique by electron capture gas chromatography including the calibration procedure which was used to achieve the complete $\mathrm{SF}_{6}$ data set presented here. The main purpose of the paper is to present new world-wide high-precision $\mathrm{SF}_{6}$ data records now covering the past $18 \mathrm{yr}$ by including samples from the unique air archive from Cape Grim, Tasmania (Fraser et al., 1991). In a similar way, as described by Maiss and Levin (1994) we use a simple two-box model of the atmosphere to explain the interhemispheric difference and to derive a long-term trend function for the tropospheric $\mathrm{SF}_{6}$ chronology in both hemispheres. The potential to apply $\mathrm{SF}_{6}$ as a transport tracer in the atmosphere and in linked compartments like the hydrosphere or the cryosphere is also discussed briefly.

\section{ANALYTICAL SYSTEM}

Analysis of sulfur hexafluoride is performed by gas chromatography using an electron capture detector (Shimadzu GC-8AIE). The system, shown schematically in Fig. 1, is a compact transportable device, primarily designed for on board $\mathrm{SF}_{6}$ analysis of water samples during a tracer release experiment in Lake Constance, Germany (Maiss et al., 1994a, b). Here we briefly summarize the major features with emphasis on routine air sample analysis for the present work.

The analytical system can be roughly divided into five components: (1) the six-port selection valve V1 to load different types of samples. It allows either the gas content of the stripper reservoir to escape during water sample injection through the vent of V3, or allows one of the two sample loops selected by valve V3 to be flushed with nitrogen (positions D and F of V1) or loaded with standard or a gas sample; (2) the extraction unit for water samples, including the stripper reservoir, the $\mathrm{Mg}\left(\mathrm{ClO}_{4}\right)_{2}$ drier, and the ten-port valve V2. During gas sample analysis, this part is used as a through pass and a switch for flushing the content of the in-line sample loop onto the trap; (3) the injection system for gas samples, being loaded through valve V1 and consisting of two sample loops selected by valve V3. Four volume calibrated loops are avail- able: $0.1040 \pm 0.0014,1.006 \pm 0.002,4.817 \pm 0.002$ and $15.024 \pm 0.002 \mathrm{~cm}^{3}$. In principle, air samples with sub-ambient pressure can be analyzed as well by connecting a vacuum system at the vent of valve V3; (4) the trapping system, namely the trap, heater/cooler and functions of valves V2 and V4; (5) the chromatographic separation and detection system, including pre- and main-column, valve $\mathrm{V} 4$, and the electron capture detector (ECD). Since components are integrated into one unit, most of the valves are involved in more than one function.

Valve switching, heating and cooling of the trap are controlled by a portable PC recording the ECD-signal and providing instantaneous peak integration. In this way, the reproducibility is improved, since only the sample injection remains manual. Standard and blank measurements are automatic. Gas samples take about $10 \mathrm{~min}$ analysis time. Ultra-high purity nitrogen further cleaned by an activated charcoal filter is used as carrier gas. This purified nitrogen is tested to be free of $\mathrm{SF}_{6}\left(<10^{-5} \mathrm{ppt}\right)$ and is used also for blank measurements. The four valves V1-V4 (Valco E-2) can be positioned electronically and have very small dead volume stainless steel rotary heads. The content of one or more sample loops is collected in the trap filled with Porapak- $Q^{\oplus}$ and cooled down to $-77^{\circ} \mathrm{C}$ by a dry-ice/isopropanol bath. The cryogenic preconcentration allows large volume samples and thus high-precision analyses of low mixing ratio samples. Electromechanical repositioning of the isolated trap between two copper blocks held at $+100^{\circ} \mathrm{C}$ completely releases the trapped $\mathrm{SF}_{6}$. Chromatographic separation starts by the injection of the heated trap content onto the precolumn $(30 \mathrm{~cm})$ which is backflushed when $\mathrm{SF}_{6}$, being the fastest component, has reached the main column $(300 \mathrm{~cm})$. This enhances sample throughput. Both columns are made of $2.4 \mathrm{~mm}$ ID stainless steel tube, packed with $5 \mathrm{~A}$ molecular sieve (80-100 mesh, Alltech), located in the GC oven and kept at $65^{\circ} \mathrm{C}$. With a carrier gas flow rate of $20 \mathrm{mlmin}^{-1}$, the $\mathrm{SF}_{6}$ peak reaches the ECD kept at $330^{\circ} \mathrm{C} 2 \mathrm{~min}$ after trap injection.

In the present work, air sample analyses were carried out with the $15.024 \mathrm{~cm}^{3}$ loop (position 2 at V3), while for standard gas analyses the $1.006 \mathrm{~cm}^{3}$ loop (position 1 at V3) was always used. All $\mathrm{SF}_{6}$ measurements are first related to our 93.7 ppt secondary standard. For testing the linearity of the system, different numbers of standard gas aliquots from the 1.006 $\mathrm{cm}^{3}$ and the $0.104 \mathrm{~cm}^{3}$ sample loop (at positions 1 and 2 of V3) were collected in the trap and analyzed. The response of the system to $\mathrm{SF}_{6}$ is linear $\left(R^{2}>0.9999\right)$ from the minimum detectable level of $0.015 \mathrm{fmol}$ up to $10 \mathrm{fmol}$ with a typical sensitivity of $22 \mathrm{mVs} \mathrm{fmol}^{-1}$ ( $1 \mathrm{fmol}=10^{-15} \mathrm{~mol}$ ). During routine analysis the sensitivity of the whole analytical system is measured by two standard gas analyses every 8 air samples. The analytical precision of a single sample is dominated by the peak area uncertainty of replicate blank measurements of $\pm 0.12 \mathrm{mVs}$ leading to an accuracy of 


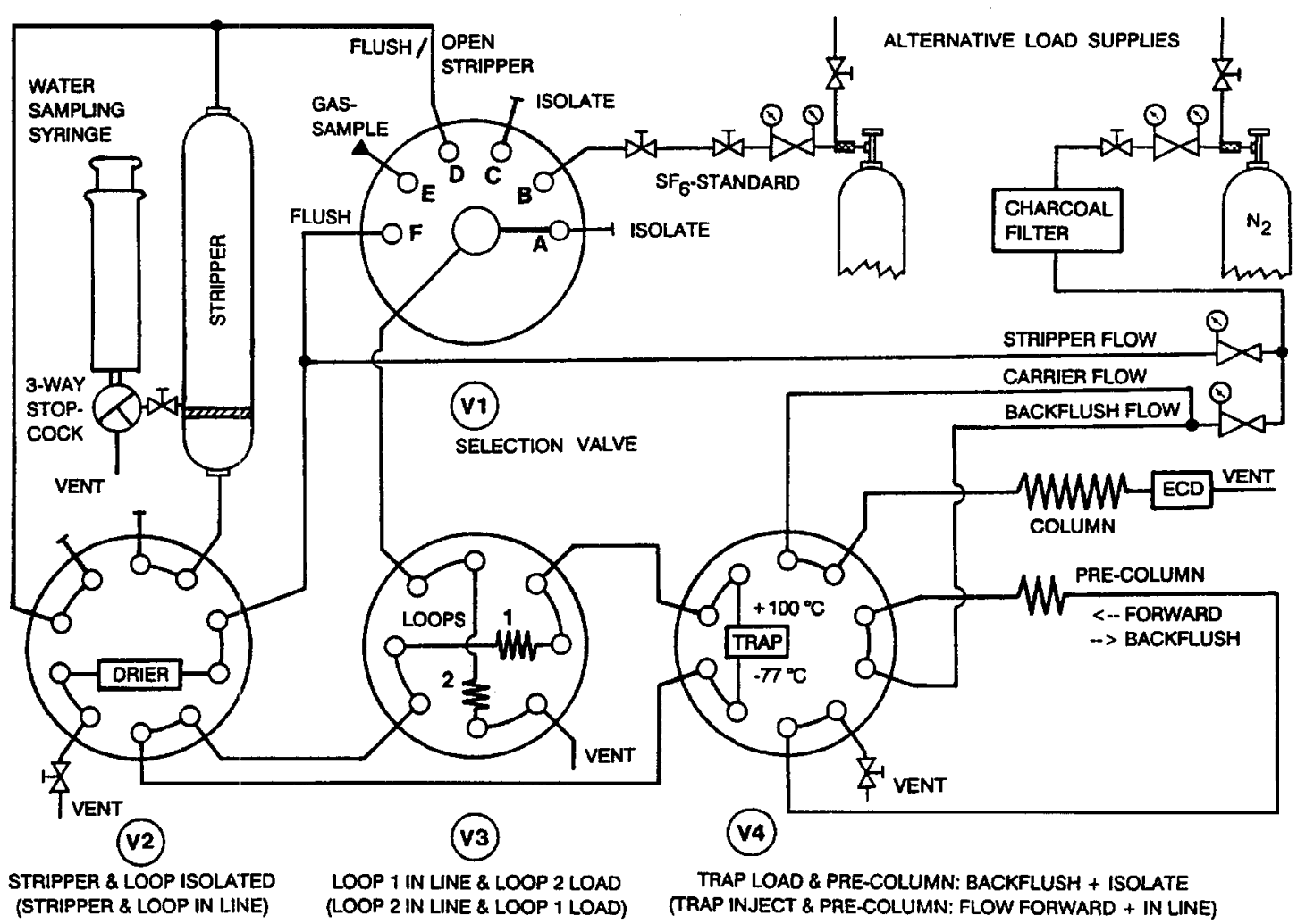

Fig. 1. $\mathrm{SF}_{6}$ analysis system: legends describe the different functions of the valves $\mathrm{V} 1-\mathrm{V} 4$ for the shown position and the reverse position in parentheses.

$\pm 1.3 \%$. Higher precision was achieved when working, in addition, with five air standards at the concentration range of 1.6-3.2 ppt. These background air standards are routizely analyzed together with the samples of unknown concentration. The results for the air standards on an individual day are used in a second evaluation step to adjust the peak area of the blank in an optimum way through least squares fitting. This procedure leads to an improvement of the blank determination: on individual days and thereby to an overall analytical precision of about $\pm 0.5 \%$. A large number of the air samples stored in aluminium or stainless steel tanks over different time periods (up to $6 \mathrm{yr}$ ) was analyzed repeatedly over the last 3 yr. No drift in concentration has been observed in these samples.

\section{CALIBRATION METHOD}

All $\mathrm{SF}_{6}$ measurements are related to our $93.7 \mathrm{ppt}$ $\mathrm{SF}_{6}$ secondary gas standard prepared in the Heidelberg laboratory from a commercially available gravimetric high pressure $0.1 \mathrm{ppm}$ (parts per million) $\mathrm{SF}_{6}$ in $\mathrm{N}_{2}$ primary standard with a certified accuracy of $\pm 1 \%$ (Messer-Griesheim, Germany). A gravimetrically controlled single step static pressure dilution with ultrapure $\mathrm{N}_{2}$ was used, giving an absolute nom- inal accuracy of our secondary gas standard of $\pm 1.1 \%$. Even though this method is simple and reliable it is not very common. Therefore we will describe the preparation procedure here in detail.

Firstly, the volume of a normal $2 \ell$ aluminium tank (Luxfer) fitted with a stainless steel valve and designated to take the final gas standard, is precisely calibrated by weighing it, repeatedly evacuating, and filling with $\mathrm{N}_{2}$ at ambient pressure and temperature. Gas density and mass difference yield the tank volume $V_{\mathrm{T}}$. Material and size of the tank were chosen to stay within the usual range of high precision scales $(4000 \mathrm{~g})$ even if filled with $200 \mathrm{~atm}$ of $\mathrm{N}_{2}$. The scale precision $( \pm 0.01 \mathrm{~g}$ ) is sufficient to calibrate a volume of about $2000 \mathrm{~cm}^{3}$ with an accuracy better than $0.5 \%$. We obtained $V_{T}=2059 \pm 10 \mathrm{~cm}^{3}$. To contain an aliquot of our primary standard (concentration $c_{\mathrm{o}}=0.1 \mathrm{ppm}$ $( \pm 1 \%))$ we used a stainless steel cylinder of calibrated volume (Nupro), $V_{\mathrm{C}}=50 \mathrm{~cm}^{3}( \pm 1 \%)$, fitted with a stainless steel valve. This cylinder was evacuated, weighed, and filled up to about 6 atm with our primary standard. Due to the lower weight of this cylinder the resulting increase in weight, $\Delta m_{\mathrm{C}}$ $=0.366 \mathrm{~g}$, is measured with a precision of $\pm 0.001 \mathrm{~g}$. The filled cylinder was then connected to the evacuated $2 \ell$ aluminium tank and its content expanded into the tank. After pressure equilibration, both containers were closed and disconnected. A $50 \ell$ tank of 
ultrapure, $\mathrm{SF}_{6}$-free $\mathrm{N}_{2}$ (200 atm) was then attached to the aluminium tank to bring it close to equilibration pressure $(\approx 190 \mathrm{~atm})$. The aluminium tank was weighed and the mass difference relative to the evacuated weight was determined $\left(\Delta m_{\mathrm{T}}=379.91 \pm 0.01 \mathrm{~g}\right)$. Even considering an unprecisely known dead volume of the fittings used for coupling the $50 \mathrm{~cm}^{3}$ cylinder to the aluminium tank $\left(V_{\mathrm{D}} \approx 7.5 \pm 1 \mathrm{~cm}^{3}\right)$, the final standard concentration $c_{\mathrm{s}}=c_{\mathrm{o}} \cdot\left\{V_{\mathrm{T}} /\left(V_{\mathrm{T}}+\right.\right.$ $\left.\left.\left.V_{\mathrm{C}}+V_{\mathrm{D}}\right)\right\} \cdot\left\{\Delta m_{\mathrm{C}}\right) / \Delta m_{\mathrm{T}}\right\}=93.7 \mathrm{ppt}$ is determined with a nominal uncertainty of $\pm 1.1 \%$ (Gaussian addition of errors) being mainly due to the $\pm 1 \%$ uncertainty of the primary standard. The assumption of ideal gas behavior is used to calculate the tank volume $V_{\mathrm{T}}$ at a pressure of $\approx 1 \mathrm{~atm}$ where the nonideal correction for $\mathrm{N}_{2}(+0.03 \%)$ can be neglected. Our calibration method needs no accurate measurement of high pressures. Only simple volume and weight determinations are to be made. A dilution factor of $\approx 10^{-5}$ can be achieved by one single step.

There is no internationally accepted gas standard for $\mathrm{SF}_{6}$ in the ppt range available, and no intercalibration with other laboratories has been undertaken so far. However, a comparison based on atmospheric background concentrations derived recently from oceanic background observations by Law et al. (1994) indicates absolute differences between the two laboratories of less than $\pm 5 \%$. Our standard was prepared gravimetrically and is, thus, defined in a mole fraction scale. Consequently, and therewith following conventional practice ( $R$. Weiss, personal communication) all concentrations given in the present paper are mole ratios.

\section{SAMPLING SITES}

Long-term observations of $\mathrm{SF}_{6}$ at four background air monitoring stations, Neumayer (Antarctica), Cape Grim (Tasmania), Izaña (Canary Islands), and Alert (Canada) are the basis of the present $\mathrm{SF}_{6}$ study. In addition to these time series, two shipboard meridional profiles of background air over the Atlantic Ocean were analyzed as well as occasional samples from the regional site Fraserdale (Canada). Except for the Cape Grim baseline station, the samples are high volume air samples originally collected for methane isotope analyses in Heidelberg (Levin et al., 1992). The six sampling sites in the northern and southern hemisphere are characterized as follows:

Neumayer (Antarctica, $71^{\circ} \mathrm{S}, 8^{\circ} \mathrm{W}, 42 \mathrm{~m}$ asl). At the German Antarctic Neumayer station, situated on the Ekström ice shelf close to the ice edge, monthly, and in later years up to weekly, spot samples of about $1 \mathrm{~m}^{3}$ of air were directly compressed into $10 \ell$ high pressure tanks using a diving compressor (Bauer, München). Before 1991 stainless steel tanks were used as sampling containers, in the later years, in most cases, we used aluminium tanks. Air sampling is controlled by wind direction to guarantee background conditions With increasing time resolution, 225 samples from October 1986 till December 1994 have been measured. This data set provides the most comprehensive quasi-continuous time series of $\mathrm{SF}_{6}$ measurements

Cape Grim (Tasmania, $41^{\circ} \mathrm{S}, 145^{\circ} \mathrm{E}, 94 \mathrm{~m}$ asl). Since 1978 air has been archived at the Cape Grim Baseline Air Pollution Station in pressurized tanks. A detailed description of the sampling technique at this station on the northwestern tip of Tasmania, Australia, is given by Fraser et al. (1991) and Weeks et al. (1992). The Cape Grim air archive has been shown to accurately represent the Cape Grim in situ record for CFC-11 and CFC-12 over the period 1978-1993 (Cunnold et al., 1994). Samples of the Cape Grim air archive were transferred to previously evacuated electropolished stainless steel flasks of 1.6 and $0.9 \ell$ volume. Typical pressure in subsamples was 200 $500 \mathrm{kPa}$ absolute, mostly achieved by direct transfer, but assisted cryogenically if the parent archive tank had a lower pressure. The integrity of the subsample was assessed by comparing measured values in parent and subsample for a full range of species measured in at CSIRO, including $\mathrm{CO}_{2}, \mathrm{CH}_{4}, \mathrm{CO}, \mathrm{H}_{2}, \mathrm{~N}_{2} \mathrm{O}$, and several CFCs. Typically, agreement was better than $2 \%$ in all cases. In the Heidelberg laboratory, $\mathrm{SF}_{6}$ analyses were performed on 44 subsamples over the time range of 1978-1994. This time series represents the longest atmospheric $\mathrm{SF}_{6}$ chronology available to date.

Izaña (Tenerife/Canary Islands, $28^{\circ} \mathrm{N}, 16^{\circ} \mathrm{W}$, $2367 \mathrm{~m}$ asl). At this high altitude maritime background observatory in the North Atlantic trade wind system operated by the Instituto Nacional de Meteorologica, Madrid, Spain, air is most of the time representative of the free mid-troposphere in this latitudinal belt (Schmitt et al., 1988). Air has been collected continuously over two weeks in high volume bags made of polyethylene coated weldable aluminium foil. These integrated samples of about $1-1.5 \mathrm{~m}^{3}$ STP were subsequently transferred to $10 \ell$ aluminium tanks using a diving compressor (Bauer, München). 85 Izaña air samples have been analyzed for $\mathrm{SF}_{6}$ since July 1991

Fraserdale (Canada, $50^{\circ} \mathrm{N}, 82^{\circ} \mathrm{W}, 200 \mathrm{~m}$ asl). Weekly integrated samples collected in 1994 have been analyzed from the regional station Fraserdale, run by the Atmospheric Environment Service (AES), Toronto, Canada. The air sampling technique is the same as used at Izaña. The Fraserdale station is located in the Hudson Bay Lowlands far away from anthropogenic sources. Moreover, trajectory analyses show that the station, for most of the time, is influenced by northerly air masses (AES, unpublished results). The station should, therefore, represent continental background conditions in mid-latitudes of the northern hemisphere.

Alert (Canada, $82^{\circ} \mathrm{N}, 63^{\circ} \mathrm{W}, 187 \mathrm{~m}$ asl). 36 samples from the High Arctic Research Laboratory, Alert, also operated by the AES, have been analyzed. The station 
is located at the northeastern strip of Ellesmere Island and is thus far removed from major industrial regions. This site is well suited to monitor the background air of the high northern latitudinal belt (Trivett and Worthy, 1989). SF $_{6}$ measurements on two-week integrated samples collected in a similar way as at Izaña and Fraserdale started in April 1993 and are available until December 199.4 except for a six week gap from 2 May to 14 June 1994.

Latitudinal profiles. High volume surface air spot samples were collected during two cruises of the German RS Polarstern on the Atlantic Ocean. In November 1990 samples were taken from $30^{\circ} \mathrm{N}$ to $68^{\circ} \mathrm{S}$ on a cruise from Germany to Antarctica, and in November 1993 we collected samples from $40^{\circ} \mathrm{N}$ to $56^{\circ} \mathrm{S}$ on a cruise from Germany to South Africa.

\section{ATMOSPHERIC SF 6 HISTORY}

Figure 2 summarizes all $\mathrm{SF}_{6}$ background observations achieved in this investigation for the northern (NH) and the southern (SH) hemisphere. Compared to the preliminary data from Neumayer and Izaña reported by Maiss and Levin (1994), the measurements presented here have more than double the precision, and are updated until December 1994. Additionally, archived air samples from Neumayer station have been analyzed together with the new samples from Alert, Fraserdale and from Cape Grim archived air. With the latter, the atmospheric chronology of $\mathrm{SF}_{6}$ is extended by $8 \mathrm{yr}$ back to 1978 .

Time-series of sulfur hexafluoride in both hemispheres show very little scatter and a steady long-term increase. The concentration in the $\mathrm{NH}$ is persistently higher when compared to the SH due to a relatively strong increase rate resulting from predominantly $\mathrm{NH}$ sources, and an interhemispheric exchange time of the order of 1-2 yr. Concentrations observed at Alert normally exceed those observed at Izaña, on average by 0.07 ppt in 1994. Maximum "background" concentrations are observed in mid-northern latitudes, at Fraserdale, exceeding concentrations observed at Izaña, on average by $0.14 \mathrm{ppt}$ in 1994 . These maximum concentrations can be explained by the fact that the main sources of $\mathbf{S F}_{6}$ are located in northern midlatitudes. For comparable sampling periods in the Southern Hemisphere (SH), the Cape Grim and Neumayer data are identical within their inherent variations. This impressively shows that, with respect to $\mathrm{SF}_{6}$, mid-to-high latitudes of the $\mathrm{SH}$ seem to be well mixed. Also before 1986, the Cape Grim data reflect a nearly perfect back-extrapolation of the long-term trend established by the Neumayer data. This means a stable and unbroken trend in the rise of atmospheric $\mathrm{SF}_{6}$ since 1978 . For the period from May 1991 to February 1992, the Neumayer record shows a concentration bump in combination with data variations larger than in the remaining part of the $\mathrm{SH}$ record. An error during sample analysis can be ex- cluded. However, since the period exactly coincides with the use of new tanks (Spectra-Seal, BOC), we are still investigating if this concentration bump comes from a small contamination in the sample containers. These debatable data are shown in Fig. 2 but have been excluded in the long-term trend fitting given below.

Both shipboard latitudinal profiles, shown by the inset of Fig. 2, are consistent with the time series. An identical concentration scale for the inset allows for direct comparison of the latitudinal distribution with the time series data. Southern hemispheric means for the troposphere of $2.34 \pm 0.03 \mathrm{ppt}$ for November 1990 and $2.91 \pm 0.02 \mathrm{ppt}$ for November 1993 are calculated by weighting the cruise data by the area of the equivalent latitude band. For the $\mathrm{NH}$, means of $2.57 \mathrm{ppt}(1990)$ and $3.15 \mathrm{ppt}$ (1993) were derived with the same method. These NH means are likely to be minimum values since missing cruise data for mid-to-high latitudes result in underestimated NH means. Therefore, based on the cruise data for the latitude of Izaña, we have used the above mentioned mean concentration shifts for the sites Fraserdale $(+0.14 \mathrm{ppt})$ and Alert $(+0.07 \mathrm{ppt})$ to create two supplementary "data points" at $50^{\circ}$ and $82^{\circ} \mathrm{N}$. These values are shown as well in the inset of Fig. 2. With these additional estimates for $50^{\circ}$ and $82^{\circ} \mathrm{N}$ we have calculated NH means again and obtain $2.67 \mathrm{ppt}$ (1990) and $3.21 \mathrm{ppt}$ (1993) as probably the more realistic values.

Maiss and Levin (1994) have already shown that, based on Neumayer observations, an extrapolation of the global increase of $\mathrm{SF}_{6}$ back to 1970 matches other historical measurements in the 1970 s and early 1980 s reasonably well. Further, using a simple two-hemispheric box model, the long-term trend of $\mathrm{SF}_{6}$ observed in the troposphere is best fitted by a quadratic increase. Linear or exponential trend curves would conflict with earlier observations and are not able to describe the onset of marked $\mathrm{SF}_{6}$ emissions in the 1960 s when the predominant industrial application in GIS systems started. Interpretation of the $\mathrm{SF}_{6}$ concentrations obtained in both this study and earlier work, requires a model for atmospheric mixing as well as for the global source distribution of $\mathrm{SF}_{6}$. For the latter we will make the following estimates:

The dominant use of $\mathrm{SF}_{6}(80 \%)$ is in heavy electrical equipment, such as gas insulated switchgear (GIS) and substations (Niemeyer and Chu, 1992). The remaining $20 \%$ is mainly used in metal industries for blanketing or degassing the molten reactive metals aluminium and magnesium (Stordal et al., 1993). In the case of GIS, the occasional release of $\mathrm{SF}_{6}$ into the atmosphere, either through small leakage from equipment or discharge during equipment repair or maintenance, should be distributed down to a country scale and directly correlated with electric power production. In 1987, the $\mathrm{NH}$ produced $94 \%, 88 \%$ and $100 \%$ of total electric power, aluminium and 


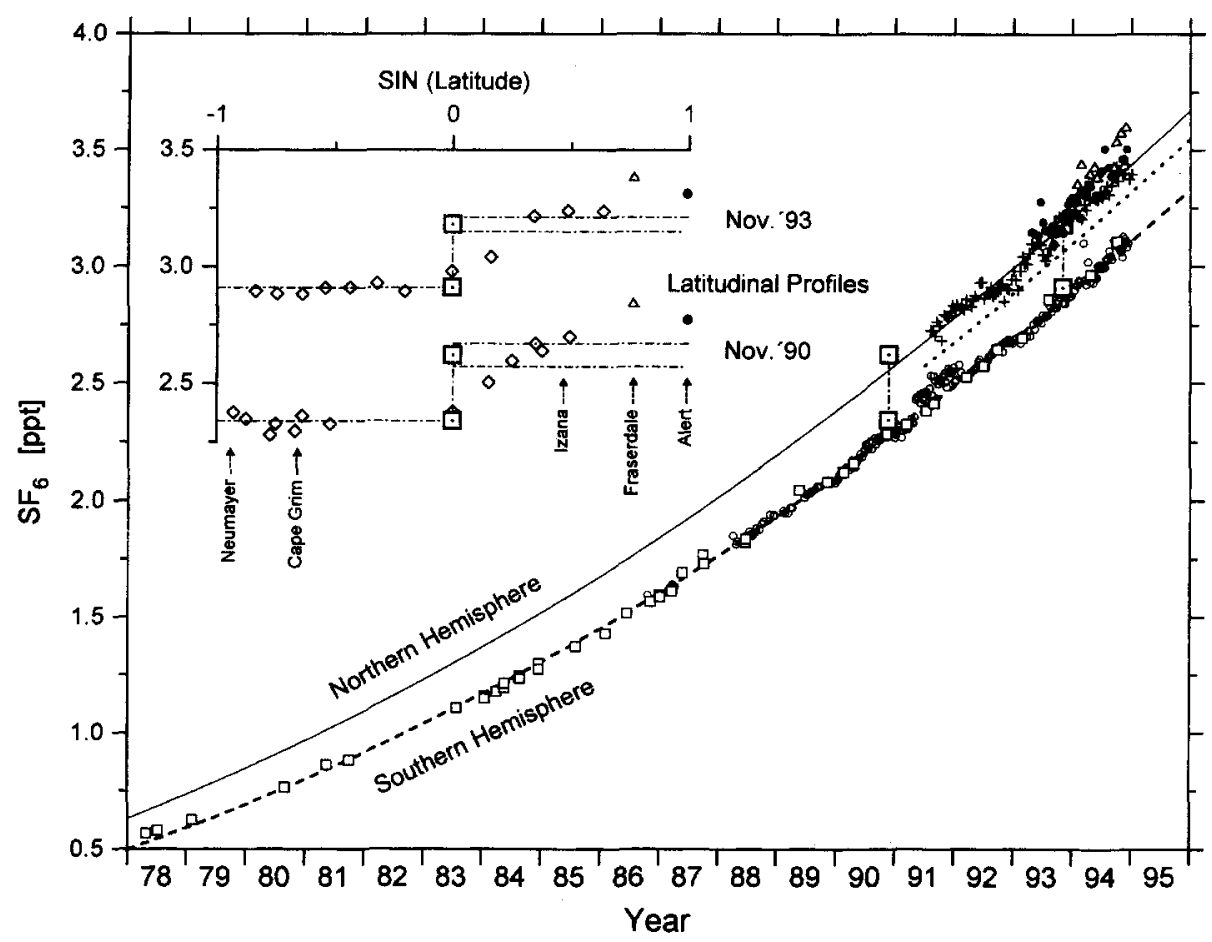

Fig. 2. $\mathrm{SF}_{6}$ observations in the atmosphere: southern hemispheric records for Neumayer station $(\mathrm{O})$ and Cape Grim $(\square)$ are based on spot samples. northern hemispheric time series for Izaña $(+)$ Alert $(\bullet)$ and Fraserdale $(\triangle)$ are obtained from one- and two-week integrated samples. Not shown are three outliers from Fraserdale and one outlier from Izaña being probably contaminated by polluted air mass plumes. The analytical uncertainty of individual data points is always below symbol size. Assuming $94 \%$ of $\mathrm{SF}_{6}$ emissions occurring in the northern hemisphere, results of a quadratic trend model fitting are given as dashed curve for the southern hemisphere and as solid and dotted curve for the northern hemisphere, using an interhemisphere exchange time of 1.7 and $1.1 \mathrm{yr}$, respectively. Inset: $(\diamond)$ Latitudinal profiles of $\mathrm{SF}_{6}$ ground level concentrations over the Atlantic Ocean. Hemisphere means are indicated by dashed-dotted lines. A second higher mean in the northern hemisphere is obtained if indicated estimates for Alert $(\bullet)$ and Fraserdale $(\Delta)$ are considered additionally. Open squares joined by a dashed-dotted line allow to link the latitudinal profiles information to the time-series of the main figure.

magnesium production, respectively. For a variety of smaller, more sophisticated $\mathrm{SF}_{6}$ uses, a $100 \%$ $\mathrm{NH}$ contribution seems realistic. If the $80 \%$ heavy electrical use of $\mathrm{SF}_{6}$ is associated with $94 \%$ of the total power production in the $\mathrm{NH}$, and the remaining $20 \%$ of $\mathrm{SF}_{6}$ uses are associated with the $88-100 \%$ use in the NH, between $93 \%$ and $95 \%$ of the total $\mathrm{SF}_{6}$ emissions occur in the NH. Prather et al. (1987) estimated a figure of $95 \%$ for the $\mathrm{NH}$ power production in 1978 , and we assume that a similar percentage of northern hemispheric $\mathrm{SF}_{6}$ emissions $(94 \pm 1 \%)$ is applicable for the period back to that time.

For a simple analytical long-term representation of our tropospheric data, a two-box mass balance model can be formulated assuming an atmospheric lifetime of $\mathrm{SF}_{6}$ much longer than its atmospheric occurrence, and an emission rate $E(t)$ of $\mathrm{SF}_{6}\left(10^{-12} \mathrm{~mol} \mathrm{yr}^{-1}\right)$ increasing linearly with time:

$$
\begin{gathered}
\mathrm{d} c_{\mathrm{NH}}(t) / \mathrm{d} t=\gamma \cdot E(t) \cdot 2 / n_{\mathrm{eff}}-\Delta c_{\mathrm{NS}}(t) \tau_{\mathrm{ex}} \\
\mathrm{d} c_{\mathrm{SH}}(t) / \mathrm{d} t=(1-\gamma) \cdot E(t) \cdot 2 / n_{\mathrm{eff}}+\Delta c_{\mathrm{NS}}(t) / \tau_{\mathrm{ex}}
\end{gathered}
$$

where $c_{\mathrm{NH}}(t)$ and $c_{\mathrm{SH}}(t)$ are the mean surface concentrations in both hemispheres; $\Delta c_{\mathrm{NS}}=c_{\mathrm{NH}}(t)-c_{\mathrm{SH}}(t)$ is the mean interhemispheric difference; $n_{\text {eff }}$ is the mass of the effective atmospheric reservoir in moles (to get the global inventory from surface concentrations); $\tau_{\text {ex }}$ is the interhemispheric exchange time and $\gamma(94 \%)$ is the ratio of NH emissions to total emissions. With time $t$ in years AD (e.g. $t=1992.0 \Leftrightarrow 1$ January 1992) and with $c_{\mathrm{NH}}\left(t_{\mathrm{o}}\right)=c_{\mathrm{SH}}\left(t_{\mathrm{o}}\right)=0$ the solution of equations (1) and (2) can be approximated for $t>\left(t_{0}+2 \mathrm{yr}\right)$ by the following quadratic time dependency for the SH:

$$
c_{\mathrm{SH}}(t)=u \cdot\left(t-t_{\mathrm{o}}\right)^{2} \quad[\mathrm{ppt}] .
$$

The values of $u$ and $t_{0}$ were derived by fitting equation (3) to the Neumayer and Cape Grim data, and found to be 0.003865 and 1966.635 , respectively. Figure 2 displays this result by a dashed curve providing an excellent representation of the observed $\mathrm{SF}_{6}$ record in the SH. Further, in terms of the revised parameters $u$ and $t_{\mathrm{o}}$ if compared to the earlier estimate of Maiss and Levin (1994), the model solution for the emission rate and the interhemispheric concentration difference 
is given by:

$$
\begin{aligned}
& E(t)=2 u n_{\mathrm{eff}}\left\{t-t_{\mathrm{o}}+\tau_{\mathrm{ex}} \cdot(\gamma-0.5)\right\} \\
& \quad\left[10^{-12} \mathrm{~mol} \mathrm{yr}^{-1}\right] \\
& \Delta c_{\mathrm{NS}}(t)=2 u \tau_{\mathrm{ex}}\left\{(2 \gamma-1)\left(t-t_{\mathrm{o}}+\tau_{\mathrm{ex}} \cdot(\gamma-1)\right)\right\}
\end{aligned}
$$

[ppt].

A value for $n_{\text {eff }}$ is only needed for emission calculations through (4). From own unpublished vertical $\mathrm{SF}_{6}$ profiles we estirnated that during the last 15 years $n_{\text {eff }}$ is at least $95 \%$ of the total atmospheric dry mass $\left(n_{\text {atm }}=1.77 \times 10^{20} \mathrm{rnol}\right)$. Neglecting this slight difference of $<5 \%\left(n_{\mathrm{eff}} \approx n_{\mathrm{atm}}\right)$ and using derived values for $u, \gamma, t_{\mathrm{o}}$ and $\tau_{\mathrm{ex}}=1.7 \mathrm{yr}$, equation (4) can be simplified to a emission rate estimate in $\mathrm{Gg} \mathrm{yr}^{-1}$ as follows: $E(t)=0.2 \cdot\{t-1965\}$. For example $5.7 \mathrm{Gg} \mathrm{yr}^{-1}$ are obtained for 1994 fitting well into emission scenarios based on earlier data (Maiss and Levin, 1994, and references therein).

Using SH fit values for $u$ and $t_{\mathrm{o}}$ and adding (5) to (3) gives the model solution $c_{\mathrm{NH}}(t)$ for the $\mathrm{NH}$. The only unknown $\tau_{\mathrm{ex}}$ is obtained by least squares fitting of $\mathcal{C}_{\mathrm{NH}}(t)$ to the Izaña data set. An interhemispheric exchange time $\tau_{\mathrm{ex}}=1.7 \pm 0.2 \mathrm{yr}$ yields the best fit for $\gamma=94 \%$ and is shown in Fig. 2 by a solid curve. A variation of $\gamma$ by $1 \%$ alters the value for $\tau_{\text {ex }}$ only by \pm 0.04 yr.

With equation (5) solved for $\tau_{\mathrm{ex}}$, interhemispheric exchange times can be calculated from the northsouth concentration difference, $\Delta c_{\mathrm{Ns}}$, derived from hemispheric means of measured latitudinal profiles as well. Depending on which of the two different estimates for the Northern Hemisperic mean (Fig. 2) the computation of $\Delta c_{\mathrm{NS}}$ is based on, a range for $\tau_{\mathrm{ex}}$ from 1.4 to $2.0 \mathrm{yr}$ and from 1.3 to $1.6 \mathrm{yr}$ is obtained for November 1990 and 1993, respectively. The minimum values for $\tau_{\mathrm{ex}}$ are obtained if only measurements up to $40^{\circ} \mathrm{N}$ are considerec. Within the obtained uncertainty ranges, the results are consistent with the long-term mean $\tau_{\mathrm{ex}}=1.7 \pm 0.2 \mathrm{yr}$ derived from the continuous data. On the other hand, the wide ranges also show how sensitive estimates of $\tau_{\mathrm{ex}}$ are on the way the $\mathrm{NH}$ means have been determined.

\section{DISCUSSION}

Agreement between the interhemispheric exchange time as derived from long-term observations and those calculated from November 1990 and November 1993 cruise results is not compelling as each measured latitudinal distribution is affected by the actual position of the Inner Tropical Convergence Zone (ITCZ) showing seasonal and interannual variations. Interhemispheric exchange times of 1.3-2.0 yr with a best long-term mean of $1.7 \mathrm{yr}$ obtained in the present work are significantly larger than the value of $1.1 \mathrm{yr}$ derived from continuous $\mathbf{S F}_{6}$ observations by Maiss and Levin (1994) in a previous study. This has two reasons: introducing the emission ratio $\gamma=94 \%$, thereby dropping our former assumption that $\mathrm{SF}_{6}$ is exclusively emitted in the $\mathrm{NH}$, is responsible for one half of the apparent increase of $\tau_{\mathrm{ex}}$. The second half is due to a revision of the fitting parameters $u$ and $t_{0}$ to the considerably extended SH database. Further, the time overlap of the SH and the NH records is now four years, which ensures $1.7 \pm 0.2 \mathrm{yr}$ being a more representative determination of $\tau_{\mathbf{e x}}$.

We implied as first order approximation that observations from Izaña and Neumayer (or Cape Grim) are representative means for the $\mathrm{NH}$ and the $\mathrm{SH}$ surface concentrations, respectively. Hemispheric means calculated from our latitudinal profiles justify this first order approximation. Further, two-dimensional model estimates for $\mathrm{SF}_{6}$ by Levin and Hesshaimer (1995) confirm that the concentration difference between Izaña and Neumayer (or Cape Grim) nearly exactly represents the mean concentration difference between the two hemispheres at ground level.

Weiss et al. (1983) and Jacob et al. (1987) have estimated comparative $\tau_{\mathrm{ex}}$ values of 1.7 and $1.6 \mathrm{yr}$, respectively, using hemispheric surface means of ${ }^{85} \mathrm{Kr}$ in a two-box model. With a $3 \mathrm{D}$ general circulation model, Jacob et al. (1987) have computed from the same ${ }^{85} \mathrm{Kr}$ database a distinctly lower mean $\tau_{\text {ex }}$ of $1.1 \mathrm{yr}$. They pointed out that the obvious difference in $\tau_{\mathrm{ex}}(1.1 \mathrm{yr}$ vs $1.6 \mathrm{yr})$ is due to the overestimation of the real hemispheric difference when using ground level observations in a simple two-box model of the atmosphere.

The difference between hemispheric surface means is obviously well described in a two-box model by an interhemispheric exchange time of $1.7 \pm 0.2 \mathrm{yr}$ for both transport tracers, ${ }^{85} \mathrm{Kr}$ and $\mathrm{SF}_{6}$. This is verified also by the time-lag ( $\approx \tau_{\mathrm{ex}}$ ) between representative records for surface means in each hemisphere. As shown in Fig. 2 by a dotted curve, a value $\tau_{\mathrm{ex}}=1.1 \mathrm{yr}$ does not fit the $\mathrm{SF}_{6}$ surface difference between both hemispheres. This is an important finding, since, in the past, many workers (e.g. Butler et al., 1992; Elkins et al., 1993) have used the apparently "better" 3Dmodel result for $\tau_{\mathrm{ex}}(1.1 \mathrm{yr})$ from Jacob et al. (1987) being inappropriate for a simple two-box model if working with surface data.

\section{CONCLUDING REMARKS}

All atmospheric $\mathrm{SF}_{6}$ data presented in this study confirm a stable and unbroken long-term increase of this anthropogenic trace gas which is described reasonably well by a quadratic trend model fitting the past $14 \mathrm{yr}$ of observations. This smooth and steadily increasing atmospheric $\mathrm{SF}_{6}$ concentration curve, unaffected by chemical and biological processes, and distinct for both hemispheres is a powerful tool for model investigations of transport processes in the atmosphere. With a global mean increase rate of

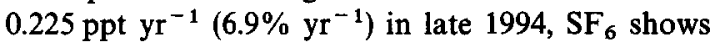
a persistently increasing trend, in contrast to CFC-11 
and CFC-12 now rising comparatively slowly as a result of production restrictions (Elkins et al., 1993). Compared to the established transport tracer ${ }^{85} \mathrm{Kr}$, $\mathrm{SF}_{6}$ is a promising alternative since it is easier to measure and both, temporally and geographically more regular in emissions. The high analytical precision now achieved in combination with an extended continuous observational network, including vertical profiles extending far up into the stratosphere, will allow the study of longitudinal, meridional and seasonal transport patterns within each hemisphere. These signals require a general three-dimensional transport model of the atmosphere for interpretation.

Beyond the promising application of $\mathrm{SF}_{6}$ as a calibration tracer to validate the transport part of complex atmospheric circulation models, the long-term observations provide an extremely valuable input function for mixing studies in linked compartments like the stratosphere, the hydrosphere and the cryosphere. Such potential applications using tropospheric background levels of $\mathrm{SF}_{6}$ are, for example, (1) troposphere/stratosphere mixing studies comparable to those performed by Schmidt and Khedim (1991) using $\mathrm{CO}_{2}$; (2) groundwater investigations (Dalmolin, 1993); (3) oceanic mixing studies from surface water to the deep ocean as proposed by Law et al. (1994); and (4) investigations of the air ventilation rate in firn (see Schwander et al. (1993) for the principal approach). A common feature in all these applications is the possibility of air sample dating with the clear tropospheric $\mathrm{SF}_{6}$ chronology applicable for the time span of the last $20 \mathrm{yr}$. Data of the present work are available on request under the E-mail address of Ingeborg Levin: LV@uphys1.uphys.uni-heidelberg.de.

Acknowledgements-We wish to thank the staff of the Neumayer, Cape Grim, Izaña, Fraserdale and the Alert observatories for carefully collecting the air samples, G. Schmedding for $\mathrm{SF}_{6}$ measurements, and V. Hesshaimer for motivating discussions on modelling questions. K. O. Münnich is gratefully acknowledged, especially for his expertise in standard preparation. We would like to thank R. Weiss for his clear words concerning the ppt-by-mole scale definition and $M$. Prather and one anonymous reviewer for their helpful comments on the manuscript.

\section{REFERENCES}

Butler J. H., Elkins J. W., Hall B. D., Cummings S. O. and Montzka S. A. (1992) A decrease in the growth rate of atmospheric halogen concentrations. Nature 359, 403-405.

Cunnold D., Fraser P., Weiss R., Prinn R., Simmonds P., Miller B., Alyea F. and Crawford A. (1994) Global trends and annual releases of $\mathrm{CFC}-11$ and $\mathrm{CFC}-12$ estimated from ALE/GAGE and other measurements from July 1978 to June 1991. J. geophys. Res. 99, 1107-1126.

Dalmolin J. (1993) Sulfur hexafluoride $\left(\mathrm{SF}_{6}\right)$ as tracer for groundwater transport processes. M.A. thesis in German language, Institut für Umweltphysik, University of Heidelberg, INF 366, 69120 Heidelberg.

Elkins J. W., Thompson T. M., Swanson T. H., Butler J. H., Hall B. D., Cummings S. O., Fisher D. A. and Raffo A. G.
(1993) Decrease in the growth rates of atmospheric chlorofluorocarbons 11 and 12. Nature 364, 780-783.

Encyclopedia of Chemical Technology (1980) Vol. 10, 3rd ed. Wiley, New York.

Fraser P. J., Langenfelds R., Derek N. and Porter L. W. (1991) Studies in air archiving techniques. Part 1: Long term stability of atmospheric trace gases in dry, natural air stored in high-pressure, surface treated aluminium cylinders. In: Baseline Atmospheric Program (Australia) 1989. (edited by WilsonS, R. and Gras J. L.), pp. 16-29. Department of the Arts, Sport, the Environment, Tourism and Territories and CSIRO.

Jacob D. J., Prather M. J., Wofsy S. C. and McElroy M. B. (1987) Atmospheric distribution of ${ }^{85} \mathrm{Kr}$ simulated with a general circulation model. J. geophys. Res. 92, 6614-6626.

Ko M. K. W., Sze N. D., Wang W.-C., Shia G., Goldman A., Murcray F. J., Murcray D. G. and Rinsland C. P. (1993) Atmospheric sulfur hexafluoride: sources, sinks and greenhouse warming. J. geophys. Res. 98, 10,499-10,507.

Law C. S., Watson A. J. and Liddicoat M. I. (1994) Automated vacuum analysis of sulphur hexafluoride in seawater: derivation of the atmospheric trend (1970-1993) and potential as a transient tracer. Marine Chemistry 48(1), $57-69$.

Levin I. and Hesshaimer V. (1995) Refining of atmospheric transport model entries by the globally observed passive tracer distribution of ${ }^{85} \mathrm{Krypton}$ and sulfur hexafluoride $\left(\mathrm{SF}_{6}\right)$ J. geophys. Res. (submitted).

Levin I., Bösinger R., Bonani G., Francey R. J., Kromer B., Münnich K. O., Suter M., Trivett N. B. A. and Wölfli W. (1992) Radiocarbon in atmospheric carbon dioxide and methane: Global distribution and trends. In Radiocarbon After Four Decades-An Inter-disciplinary Perspective (edited by Taylor R. E., Long A. and Kra R. S.), pp. 503-517. Springer, New York.

Lovelock J. E. (1971) Atmospheric fluorine compounds as indicators of air movements. Nature 230, 379.

Maiss M. and Levin I. (1994) Global increase of SF 6 observed in the atmosphere. Geophys. Res. Lett. 21, 569-572.

Maiss M., Ilmberger J. and Münnich K. O. (1994a) Vertical mixing in Uberlingersee (Lake Constance) traced by $\mathrm{SF}_{6}$ and heat. Aquatic Sci. 56/4, 329-347.

Maiss M., Ilmberger J., Zenger A. and Münnich K. O. (1994b) A SF 6 tracer study of horizontal mixing in Lake Constance. Aquatic Sci. 56/4, 307-328.

Morris R. A., Miller T. M., Viggiano A. A., Paulson J. F., Solomon S. and Reid G. (1995) Effects of electron and ion reactions on atmospheric lifetimes of fully fluorinated compounds. J. geophys. Res. 100, 1287-1294.

Niemeyer L. and Chu F. Y. (1992) $\mathrm{SF}_{6}$ and the atmosphere. IEEE Trans. Electrical Insulation 27, 184-187.

Prather M., McElroy M., Wofsy S., Russell G. and Rind D. (1987) Chemistry of the global troposphere: fluorocarbons as tracers of air motion. J. geophys. Res. 92, 6579-6613.

Ravishankara A. R., Solomon S., Turnipseed A. A. and Warren R. F. (1993) Atmospheric lifetimes of long-lived halogenated species. Science 259, 194-199.

Rinsland C. P., Brown L. R. and Farmer C. B. (1990) Infrared spectroscopic detection of sulfur hexafluoride $\left(\mathrm{SF}_{6}\right)$ in the lower stratosphere and upper troposphere. J. geophys. Res. 95, 5577-5585.

Schmidt U. and Khedim A. (1991) In situ measurements of carbon dioxide in the winter arctic vortex and at midlatitudes: An indicator of the 'age' of stratospheric air. Geophys. Res. Lett. 18, 763-766.

Schmitt R., Schreiber B. and Levin I. (1988) Effects of longrange transport on atmospheric trace constituents at the baseline station Tenerife (Canary Islands). J. atmos. Chem. 7, 335-351.

Schwander J., Barnola J.-M., Andrié C., Leuenberger M., Ludin A., Raynaud D. and Stauffer B. (1993) The age of 
the air in the firn and ice at Summit, Greenland. J. geophys. Res. 98, 2831-2838.

Stordal F., Innset B., Grossmann A. S. and Myhre G. (1993) $S_{6}$ as a greenhouse gas: an assessment of Norwegian and global sources and the global warming potential. NILU Report 15/93, Norvegian Institute for Air Research., P.O. Box 64, 2001 Lillestrøm, Norway.

Trivett N. B. A. and Worthy D. E. J. (1989) Analysis and interpretation of trace gas measurements at Alert, NWT, with emphasis on $\mathrm{CO}_{2}$ and $\mathrm{CH}_{4}$. In: Proc. 3rd Int. Conf. on analysis and evaluation of atmospheric $\mathrm{CO}_{2}$ data, present and past. WMO Report 59.
Wanninkhof R., Ledwell J. R. and Watson A. J. (1991) Analysis of sulfur hexafluoride in seawater. $J$. geophys. Res. 96, 8733-8740.

Weeks I., Francey R., Beardsmore D. and Steele L. P. (1992) Studies in air archiving. Part 2: Filling high pressure cylinders with baseline air. Baseline Atmospheric Program (Australia) 1990 (edited by Wilson S. R. and Gras J. L.), pp. 16-23. Department of Administrative Services and CSIRO.

Weiss W., Sittkus A., Stockburger H. and Sartorius H. (1983) Large-scale atmospheric mixing derived from meridional profiles of Krypton 85. J. geophys. Res. 88, 8574-8578. 